\title{
Characterization of Native and Modified Starches by Potentiometric Titration
}

\author{
Diana Soto, Jose Urdaneta, and Kelly Pernia \\ Laboratorio de Polímeros y Reacciones, Escuela de Ingeniería Química, Facultad de Ingeniería, Universidad del Zulia, \\ Sector Grano de Oro, Avenida 16 (Guajira), Ciudad Universitaria Dr. Antonio Borjas Romero, Edificio Petróleo y Química, \\ Maracaibo 4011, Venezuela \\ Correspondence should be addressed to Diana Soto; dsoto@fing.luz.edu.ve
}

Received 1 September 2014; Revised 10 November 2014; Accepted 18 November 2014; Published 3 December 2014

Academic Editor: Parsotam H. Parsania

Copyright ( $\odot 2014$ Diana Soto et al. This is an open access article distributed under the Creative Commons Attribution License, which permits unrestricted use, distribution, and reproduction in any medium, provided the original work is properly cited.

The use of potentiometric titration for the analysis and characterization of native and modified starches is highlighted. The polyelectrolytic behavior of oxidized starches (thermal and thermal-chemical oxidation), a graft copolymer of itaconic acid (IA) onto starch, and starch esters (mono- and diester itaconate) was compared with the behavior of native starch, the homopolymer, and the acid employed as a graft monomer and substituent. Starch esters showed higher percentages of acidity, followed by graft copolymer of itaconic acid and finally oxidized starches. Analytical techniques and synthesis of modified starches were also described.

\section{Introduction}

Titration is an analytical technique commonly used in many research and industrial chemistry applications. This involves the measured addition of a solution of known concentration of chemical (titrant) to determine the concentration of another chemical (analyte) in a second solution. The chemical in the titrant reacts in a known manner with the analyte material. When the reaction of these chemicals/materials is complete, a surplus of the titrant is detected as a specific end point marking the end of titration. The end point can be determined by several methods: indicators of $\mathrm{pH}$, redox indicators, potentiometry, conductometry, isothermal calorimetry, spectrophotometry, and amperometry [1].

Analytical techniques for this research included potentiometric titration. Potentiometric titration, based on the measurement of $\mathrm{pH}$ changes, is a versatile technique with a wide range of applications. It is a well-established analytical method always effective for simple acid-base systems [2, 3 ]. For over 70 years it has been applied to study macromolecules, whose early use was limited to the analysis of the behavior of proteins. At that time, the application for studying acid synthetic polymers was applied almost exclusively to poly(acrylic acid) and poly(methacrylic acid) [4]. Nowadays it is still used to investigate the dissociation behavior of poly(acrylic acid) [5] but has expanded to study poly(itaconic acid) $[6,7]$, copolymers of maleic acid with various olefins [5], styrene [8], and ionization amphiphilic diblock and triblock copolymers [9]. In this study the use of potentiometric titration for the characterization of native and modified starches technique is highlighted.

The soluble natural polymers include polynucleotides, polypeptides, and polysaccharides such as starch, cellulose, and chitosan. Due to increased interest in the use of polysaccharides for a wide range of practical applications, potentiometric titration has become a standard method to analyze specific properties of polyelectrolytes in this group. The technique has been widely used to determine the amylose content in the starch [10-14], the degree of deacetylation of chitosan $[15,16]$, and the degree of protonation of cellulose derivatives [17], among other applications.

Starch is the main storage carbohydrate in plants. It is stored as granules in most plant cells and in this state is called native starch. Native starches from different botanical sources vary widely in structure and composition, but all granules are mainly formed by two molecular components, amylose $(20-30 \%)$ and amylopectin (70-80\%) [18]. It is a food and an important basic engineering building product widely applied 
in various branches of the food industry (milk, meat, canned goods, and pastries) and in nonfood technologies, such as paper, textiles, adhesives, and pharmaceutical [19]. Industrial use is based on the adhesive and thickening properties, the ability to form films and gels, as well as its low cost and quality control [20-22].

However, this polysaccharide has unfavourable properties such as low shear strength, ease of thermal decomposition, and high tendency for retrogradation (crystallization and aging of gels), limiting its use in other applications. These properties can be overcome by chemical and/or physical modification [23]. The structure and properties of polysaccharides, such as starch, can be modified through grafting reactions, oxidation, etherification, esterification, and crosslinking, among others [24].

Starch oxidation using $\mathrm{KMnO}_{4}$, grafting, or esterification with organic acids, such as itaconic acid, generates structural changes in the starch by incorporating carboxyl groups $-\mathrm{COOH}$ [25], which gives the starch superhydrophilicity and acidity [24]. The presence of $-\mathrm{COOH}$ groups allows for the characterization of these starch derivatives via potentiometric titration.

In this study modified starches were synthesized. The polyelectrolytic behavior of oxidized starches (thermal and thermal-chemical oxidation), a graft copolymer of itaconic acid (IA) onto starch, and starch esters (mono- and diester itaconate) was compared with the behavior of native starch, the homopolymer, and the acid employed as a graft monomer and substituent.

\section{Experimental}

2.1. Materials. Food grade corn starch supplied by Alfonzo Rivas \& Cía; hydrochloric acid, $\mathrm{HCl}$ (37\%); nitric acid, $\mathrm{HNO}_{3}$ (65\%); silver nitrate, $\mathrm{AgNO}_{3}$ (>99.9\%); potassium permanganate, $\mathrm{KMnO}_{4}$ (99\%) from Fisher Scientific; ammonium hydroxide, $\mathrm{NH}_{4} \mathrm{OH}$ (95\%); iodine, $\mathrm{I}_{2}$ (99.9\%); potassium iodide, KI (100.5\%) from J.T. Baker; hydroxylamine hydrochloride, $\mathrm{NH}_{2} \mathrm{OH} \cdot \mathrm{HCl}$ (99\%); ethanol, $\mathrm{C}_{2} \mathrm{H}_{5} \mathrm{OH}$ (99.9\%); acetone, $\mathrm{CH}_{3}(\mathrm{CO}) \mathrm{CH}_{3}$ (99.9\%); ammonium persulfate (APS), $\left(\mathrm{NH}_{4}\right)_{2} \mathrm{~S}_{2} \mathrm{O}_{8}(\geq 98.5 \%)$; itaconic acid (IA), $\mathrm{C}_{3} \mathrm{H}_{4}(\mathrm{COOH})_{2}(\geq 99 \%)$; sodium hydroxide, $\mathrm{NaOH}(99 \%)$ from Merck; sodium bisulfite, $\mathrm{NaHSO}_{3}$ (Mallinckrodt Baker, 66.9\%); and potassium bromide, $\mathrm{KBr}$ (Riedel-de-Haen, 99.5\%), were all used as received.

\subsection{Sample Preparation}

2.2.1. Oxidized Starches. Oxidation by hydrothermal treatment involved the preparation of an aqueous dispersion of $10 \% \mathrm{~m} / \mathrm{v}$ (10 g dry basis corn starch, equivalent to 0.062 moles of anhydroglucose units (AGU) in $100 \mathrm{~mL}$ of distilled water). The dispersion was heated to $75^{\circ} \mathrm{C}$ for $15 \mathrm{~min}$ with gentle shaking to promote starch gelatinization. Once formed, the starch paste and $200 \mathrm{~mL}$ of distilled water were added and cooled to the reaction temperature $\left(60^{\circ} \mathrm{C}\right) .300 \mathrm{~mL}$ distilled water were added and the starch was oxidized by heat treatment (Ht-St) after $3 \mathrm{~h}$.
For the thermal-chemical oxidation, after cooling the slurry to $60^{\circ} \mathrm{C}, 0.63 \mathrm{~g}\left(4 \times 10^{-3}\right.$ moles) of $\mathrm{KMnO}_{4}$ (oxidizing initiator) and $1.04 \mathrm{~g}$ (0.01 moles) of $\mathrm{NaHSO}_{3}$ (reducing activator) were added and kept at $60^{\circ} \mathrm{C}$ for $10 \mathrm{~min}$ in order to preoxidize the starch. The volume of distilled water was immediately made up to $500 \mathrm{~mL}$ and allowed to react for $3 \mathrm{~h}$ to obtain the oxidized starch by thermal-chemical treatment (Ox-St).

In both oxidations, the product obtained was cooled to room temperature and precipitated with ethanol. The oxidized starch was washed with a mixture of $50 \% \mathrm{v} / \mathrm{v}$ ethanol/water and dried at $40^{\circ} \mathrm{C}$ to constant weight.

2.2.2. Poly(itaconic acid). Poly(itaconic acid) (PIA) was synthesized thermally using a modification of a classic method developed by Marvel and Shepherd in 1959 [26]. The reaction was conducted in a $100 \mathrm{~mL}$ Schlenk containing $50 \mathrm{~mL}$ of degassed distilled water by three alternating cycles of vacuum and nitrogen supplies. Then, $2.1 \mathrm{~mL}$ of 12.02 moles/L $\mathrm{HCl}$ $(37 \% \mathrm{~m} / \mathrm{m}), 10 \mathrm{~g}(0.0768 \mathrm{moles})$ of IA, and $0.5020 \mathrm{~g}(2.2$ $\times 10^{-3}$ moles) of APS (thermal decomposition initiator) were quickly added. The loaded Schlenk was immersed in a thermal bath of silicone oil, at $60^{\circ} \mathrm{C}$ (controlled temperature) for $44 \mathrm{~h}$. After this time the solution was cooled to room temperature and slowly poured into excess acetone for precipitating the polymer. The precipitate was redissolved in water and dried on a lyophilizer to remove both free and bound water. After lyophilization, it was washed with acetone for three days, changing the solvent every $24 \mathrm{~h}$ to remove residual monomer. Finally, the homopolymer was dried under vacuum to constant weight and stored over silica gel for further characterization.

2.2.3. Graft Copolymer of Itaconic Acid onto Starch. The same thermal-chemical oxidation procedure was used but after the preoxidation of the starch, the monomer (IA) previously dissolved in $180 \mathrm{~mL}$ of distilled water was added. The volume was immediately made up to $500 \mathrm{~mL}$ with distilled water. This time was regarded as the initial time of reaction $(0.18 \mathrm{moles} / \mathrm{L}$ IA). After $3 \mathrm{~h}$, the reaction was stopped, and the product (St-g-IA) was precipitated with ethanol. Subsequently, it was washed with a mixture of $50 \% \mathrm{v} / \mathrm{v}$ ethanol/water to remove any residual monomer, homopolymer, and fragments of soluble starch in cold water. Washing was performed until iodine testing (detection of starch) and Baeyer testing (detection of residual monomer) were negative and the $\mathrm{pH}$ of washing water was equal to or very close to that of the original washing mixture. Finally, samples were dried in an oven at $40^{\circ} \mathrm{C}$ to constant weight.

2.2.4. Itaconic Acid Starch Esters. The esterification reactions were carried out using a combination of procedures in the literature $[27,28]$. For obtaining itaconate starch semiester or starch semi-itaconate (SI), $200 \mathrm{~mL}$ of distilled water and $20 \mathrm{~mL}$ of 0.5 moles/L NaOH were added in a 3-neck flask containing $6.25 \mathrm{~g}$ starch dry basis ( 0.1754 moles/L AGU) and gelatinized for $10 \mathrm{~min}$ at $80^{\circ} \mathrm{C}$, with $\mathrm{pH}$ monitoring (2.9). 
$16.0386 \mathrm{~g}$ of esterifying agent ( $0.5604 \mathrm{moles} / \mathrm{L}$ IA) was added and heated at $80^{\circ} \mathrm{C}$ for $4 \mathrm{~h}$.

The same procedure was used for the itaconate starch diester or starch di-itaconate (DI) but a solution of $150 \mathrm{~mL}$ (0.2269 moles/L AGU and 0.7252 moles/L IA) in water was used. Then after the first $4 \mathrm{~h}$ of reaction, $18.75 \mathrm{~g}$ of starch on a dry basis dispersed in $50 \mathrm{~mL}$ of water $(0.1875$ moles $/ \mathrm{L}$ AGU) was added and heated at $80^{\circ} \mathrm{C}$ for another $4 \mathrm{~h}(0.7015$ moles/L AGU and 0.5604 moles/L IA). The reaction product was precipitated with ethanol; the precipitate was filtered and washed with ethanol until the Baeyer test was negative. The samples were dried in an oven at $40^{\circ} \mathrm{C}$ until constant weight was reached.

\subsection{Characterization of Samples}

2.3.1. FTIR. In all cases, the formation of the desired starch derivative was confirmed by infrared Fourier transform spectroscopy (FTIR). The spectra were taken on a Shimadzu IR Prestige spectrophotometer in the range of $4000-400 \mathrm{~cm}^{-1}$, using $\mathrm{KBr}$ pellets.

2.3.2. Potentiometric Titration. In this section the experimental procedure used for the potentiometric titration of different starch derivatives (Ht-St, Ox-St, St- $g$-IA, SI, and DI) of native corn starch (St), the homopolymer (PIA) and itaconic acid (IA), is detailed. All solutions used were prepared using distilled water. The $\mathrm{NaOH}$ was titrated with 0.1 moles/L $\mathrm{HCl}$ before use. Titrations were carried out with gentle shaking at room temperature controlled at $22^{\circ} \mathrm{C}$ using a $\mathrm{pH}$ meter BOECO BT-500. Stabilizing the dispersion was allowed for 2 min between each addition of titrant to ensure equilibrium. Titration curves were obtained by analyzing the gel fraction of the product separated by leaching with hot water. For this, the samples were placed in filter paper bags and immersed in beakers with $400 \mathrm{~mL}$ of distilled water at $60^{\circ} \mathrm{C}$; the change of leaching water was performed every $24 \mathrm{~h}$ until iodine test was negative.

(1) Potentiometric Titration of Itaconic Acid and Poly(itaconic acid). A volume of $25 \mathrm{~mL}$ of 0.5 moles/L IA solution and another of PIA were prepared with similar mass concentrations, since it was not possible to determine the molar mass of the PIA. In both cases the titrant was 0.1 moles $/ \mathrm{L} \mathrm{NaOH}$.

(2) Carboxyl Content. The carboxyl content of oxidized starch was determined according to the modified procedure of Chattopadhyay et al. [29]. About $0.2 \mathrm{~g}$ of starch sample was mixed with $2.5 \mathrm{~mL}$ of $0.1 \mathrm{moles} / \mathrm{L} \mathrm{HCl}$, and the slurry was stirred occasionally for $30 \mathrm{~min}$ with a magnetic stirrer. The slurry was then vacuum-filtered and washed with $40 \mathrm{~mL}$ of distilled water. The starch cake was then carefully transferred into a $50 \mathrm{~mL}$ beaker, and the volume was adjusted to $30 \mathrm{~mL}$ with distilled water. The starch slurry was heated in a boiling water bath with continuous stirring for $15 \mathrm{~min}$ to ensure complete gelatinization. The hot starch dispersion was then adjusted to $45 \mathrm{~mL}$ with distilled water and titrated to $\mathrm{pH}$ 8.3 with standardized 0.01 moles/L $\mathrm{NaOH}$. A blank test was performed without sample. Carboxyl content was calculated as follows:

meq of acidity $/ 100 \mathrm{~g}$ starch

$$
\begin{array}{r}
=\frac{\left[\left(V_{s}-V_{b}\right) \mathrm{mL} \times C_{\mathrm{NaOH}} \times 100\right]}{\text { Sample weight }(\text { dry basis }) \text { in } \mathrm{g}} \\
\% \text { carboxyl }=\left[\frac{\text { meq of acidity }}{100 \mathrm{~g} \text { starch }}\right] \times 0.045,
\end{array}
$$

where meq are milliequivalents, $V_{s}$ and $V_{b}$ are the volumes of $\mathrm{NaOH}$ consumed by the sample and the blank, respectively, and $C_{\mathrm{NaOH}}$ is the concentration of $\mathrm{NaOH}$ in moles/L.

(3) Carbonyl Content. The carbonyl content was determined by the titration method of Smith [30], with slight modifications. $0.4 \mathrm{~g}$ of starch sample was suspended in $10 \mathrm{~mL}$ distilled water in a $50 \mathrm{~mL}$ flask. The suspension was gelatinized in a boiling water bath for $20 \mathrm{~min}$, cooled to $40^{\circ} \mathrm{C}$, adjusted to $\mathrm{pH} 3.2$ with $0.1 \mathrm{moles} / \mathrm{L} \mathrm{HCl}$, and added with $1.5 \mathrm{~mL}$ of hydroxylamine reagent. The flask was stoppered and placed in a $40^{\circ} \mathrm{C}$ water bath for $4 \mathrm{~h}$ with slow stirring. The excess hydroxylamine was determined by rapidly titrating the reaction mixture to $\mathrm{pH} 3.2$ with standardized 0.1 moles/L $\mathrm{HCl}$. A blank determination with only hydroxylamine reagent was performed in the same manner. The hydroxylamine reagent was prepared by first dissolving $25 \mathrm{~g}$ hydroxylamine hydrochloride in $100 \mathrm{~mL}$ of $0.5 \mathrm{~mol} / \mathrm{L} \mathrm{NaOH}$ before the final volume was adjusted to $500 \mathrm{~mL}$ with distilled water. It was calculated as follows:

$$
\% \text { carbonyl }=\frac{\left[\left(V_{s}-V_{b}\right) \mathrm{mL} \times \mathrm{C}_{\mathrm{HCl}} \times 0.028 \times 100\right]}{\text { Sample weight }(\text { dry basis }) \text { in } \mathrm{g}},
$$

where $V_{s}$ and $V_{b}$ are the volumes of $\mathrm{HCl}$ consumed by the sample and the blank, respectively, and $C_{\mathrm{HCl}}$ is the concentration of $\mathrm{HCl}$ in moles/L.

(4) Degree of Substitution (DS) of the Esters. The DS of the esters was determined using a modified method reported by Zhu et al. [31]. A $0.5 \mathrm{~g}$ of the sample was weighed into a $250 \mathrm{~mL}$ Erlenmeyer flask; $25 \mathrm{~mL}$ of distilled water and three drops of phenolphthalein were added to flask and blended. Then $25 \mathrm{~mL}$ of 0.5 moles/ $\mathrm{L} \mathrm{NaOH}$ was added; the flask was stoppered and vigorously shaken for $30 \mathrm{~min}$ at room temperature to promote the hydrolysis of the $-\mathrm{COOH}$ groups. After that time, the flask was carefully uncovered and the plug waste and the walls were washed with distilled water and the excess alkali was titrated with 0.5 moles/L HCl until the phenolphthalein pink color disappeared $(\mathrm{pH}=7.0)$; it was allowed to stand for $2 \mathrm{~h}$ to see if the solution was turning pink again. The blank test was done with raw starch. It was calculated as follows:

$$
\begin{gathered}
\% \text { itaconyl }=\frac{\left[\left(V_{s}-V_{b}\right) \mathrm{mL} \times C_{\mathrm{HCl}} \times 0.1131 \times 100\right]}{\text { Sample weight }(\text { dry basis }) \text { in } \mathrm{g}}, \\
\mathrm{DS}=\frac{162 \times \% \text { itaconyl }}{[113.1 \times 1000-(112.1 \times \% \text { itaconyl })]},
\end{gathered}
$$




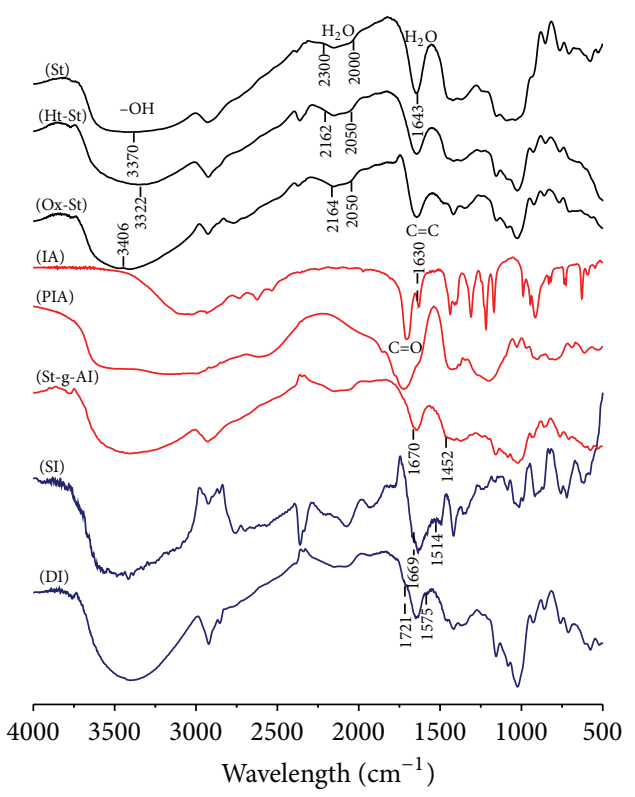

FIGURE 1: FTIR spectra of the analyzed products.

where $V_{s}$ and $V_{b}$ are the volumes of $\mathrm{HCl}$ consumed by the sample and the blank, respectively, and $C_{\mathrm{HCl}}$ is the concentration of $\mathrm{HCl}$ in moles/L.

\section{Results and Discussion}

3.1. FTIR. In Figure 1, FTIR spectra of the products obtained are shown. The oxidation of starch was confirmed in the FTIR spectra of Ox-St and Ht-St. The decrease in the area ratios between the absorption bands at $3925 \mathrm{~cm}^{-1}(-\mathrm{OH})$ and from 2000 to $2300 \mathrm{~cm}^{-1}\left(\mathrm{H}_{2} \mathrm{O}\right)$ compared to the native starch (St) indicates a reduction of $-\mathrm{OH}$ groups due to its oxidation.

In the same way, the absence of the signal of the $\mathrm{C}=\mathrm{C}$ stretch at $1630 \mathrm{~cm}^{-1}$ in the FTIR spectrum of the PIA indicated the formation of the homopolymer by the monomer double bond. The formation of the graft copolymer was confirmed through changes in the tightly bound water signal at $1646 \mathrm{~cm}^{-1}$. Over that one, a shoulder was observed at approximately $1670 \mathrm{~cm}^{-1}$ attributable to the stretching of $\mathrm{C}=\mathrm{O}$ of $-\mathrm{COOH}$. At $1452 \mathrm{~cm}^{-1}$, another signal was observed that was attributable to a weak interaction in the bending plane of the bound -C-O-H of a carboxylic acid $[32,33]$.

Characterization by FTIR of the esters confirmed their formation through the signals at 1669 and $1721 \mathrm{~cm}^{-1}$ observed in spectra of the SI and DI and attributed to the carbonyl group of the itaconate in the substituted starch, while the absorption bands at 1575 and $1514 \mathrm{~cm}^{-1}$ could be attributed to the $\mathrm{C}=\mathrm{C}$ of the itaconate and the asymmetrical deformation of the carboxylate group $\left(-\mathrm{COO}^{-}\right)$. In the fingerprint region significant changes were not observed indicating that no anhydroglucose ring opening occurred [27].

3.2. Carbonyl and Carboxyl Content of Native and Oxidized Starches. In Table 1, the results of the content of carbonyl
TABLE 1: Content of carbonyl and carboxyl groups of the oxidized starches without leaching compared to the native starch.

\begin{tabular}{lcc}
\hline Sample & $\begin{array}{c}\text { Carbonyl content } \\
(\% \mathrm{CO})\end{array}$ & $\begin{array}{c}\text { Carboxyl content } \\
(\% \mathrm{COOH})\end{array}$ \\
\hline St & $0.7927 \pm 0.0326$ & $0.0539 \pm 0.0059$ \\
Ht-St & $0.9041 \pm 0.0046$ & $0.0849 \pm 0.0039$ \\
Ox-St & $0.1502 \pm 0.0147$ & $0.1141 \pm 0.0085$ \\
\hline
\end{tabular}

and carboxyl groups of the oxidized starches compared to the native starch are shown. The assay was performed in triplicate showing that good reproducibility with an error was less than $5 \%$. The accuracy of the method was also tested by the experimental determination of the percentage of carboxyl groups of the monomer from its neutralization curve; a value of $67.08 \%$ of $-\mathrm{COOH}$ was obtained, which represents an error of $3.06 \%$ compared to the theoretical value of $69.20 \%$.

It was observed that the hydrothermal treated starch (HtSt) showed a higher content of carbonyl groups, while the content of acidic groups was greater for the oxidized starch with a redox system. From these results it can be inferred that the reaction conditions employed prolonged heat treatment to produce oxidized starch to aldehyde preferentially; such derivatives are suitable intermediates for further modifications. Meanwhile, the addition of $\mathrm{KMnO}_{4}$ favored oxidation of the hydroxyl groups of the starch to carbonyl and then carboxyl, as outlined in Figure 2. These results agree with those reported in the literature, where it is established that the $\mathrm{KMnO}_{4}$ generated primarily oxidized starches to $-\mathrm{COOH}$ with low degrees of oxidation [34-36].

3.3. Potentiometric Titration Curves of Native Starch and Oxidized Starches. In Figure 3, the titration curves of native starch (St) and oxidized starches (Ht-St and Ox-St) with 0.001 moles/ $\mathrm{L} \mathrm{NaOH}$ are shown. It is observed that all curves start at a $\mathrm{pH}$ close to 5.0; with the addition of base, the $\mathrm{pH}$ value is increased to be constant in the area of basic dominance.

The shape of the curves coincides with those reported by other researchers [19]; they also observed that the abrupt change of $\mathrm{pH}$ between 5.0 and 9.0 corresponds to the dissociation of the acid groups present in the starch. When comparing potentiometric titration curves characteristic of oxidized starches, their movement to the right is observed with respect to the native starch. The increase in acid groups such as displacement occurs, a fact that can be verified with the contents of $-\mathrm{COOH}$, whose increasing order is $\mathrm{St}<\mathrm{Ht}-\mathrm{St}$ $<$ Ox-St.

3.4. Potentiometric Titration Curves of the Monomer, Homopolymer, and Graft Copolymer. Titration curves with $\mathrm{NaOH}$ for the monomer and homopolymer are shown in Figure 4(a). It can be seen that even though the IA is a dicarboxylic acid it showed the characteristic behavior of the monoprotic weak acids; only a buffer region (single $\mathrm{pKa}$ ) and one equivalence point were observed. The behavior found is explained by the proximity of their $\mathrm{pKa}$ values $(\mathrm{pKal}=3.85$ and $\mathrm{pKa} 2=5.45)$, 


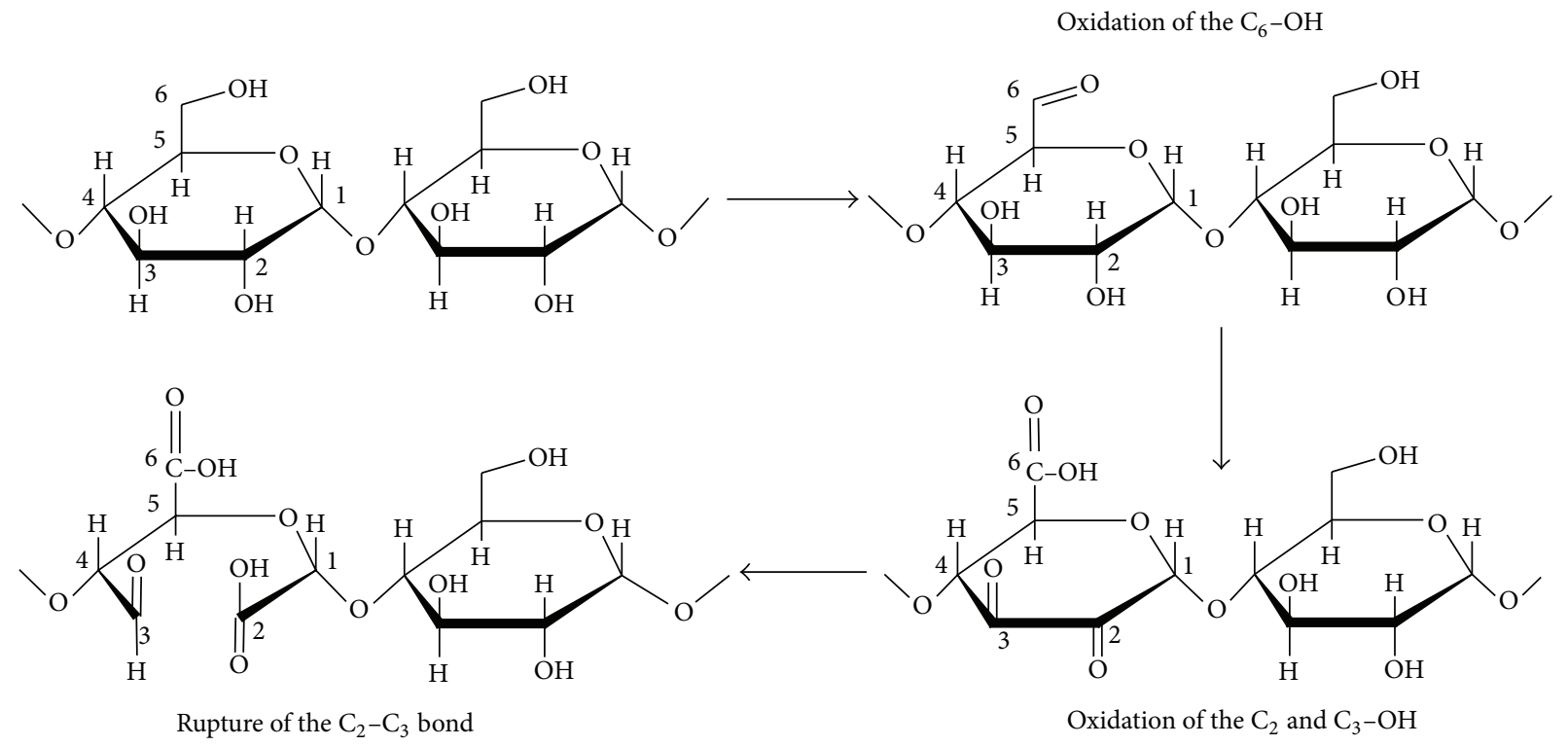

FIGURE 2: Schematic representation of the steps in the oxidation of starch in the order of reactivity of the hydroxyl groups.

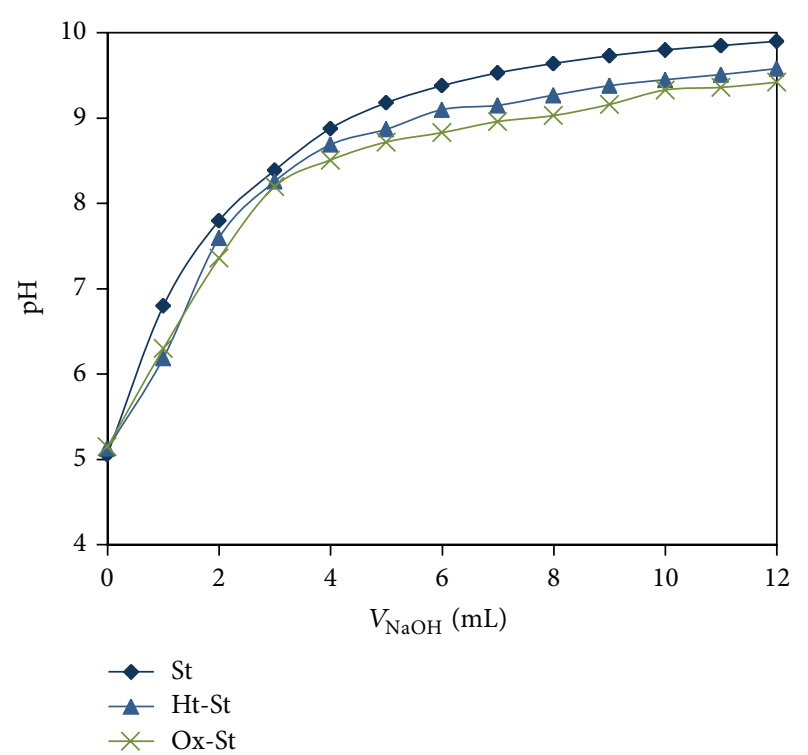

FIGURE 3: Potentiometric titration curves of native starch $(\mathrm{St})$ and hydrothermal treated (Ht-St) and oxidized (Ox-St) starches.

so that ionization of the two acidic hydrogens simultaneously occurs, causing a higher slope detected in the buffer region. Indeed, the pKa value determined from the curve was 4.87, very close to the average of the pKa value (4.65). The equivalence point is detected when approximately $20.5 \mathrm{~mL}$ of base was added to a $\mathrm{pH}$ of 9.05; by basic hydrolysis of the sodium di-itaconate formed at this point of the titration.

Comparing the neutralization curve of the monomer to the homopolymer, it can be observed that the PIA is located above the IA, because the carboxylic acid groups are less exposed than in the monomer, so it is more difficult to neutralize them, thereby generating higher $\mathrm{pH}$ and a higher volume of base required to reach the area of basic dominance.

During the neutralization of high molar mass compounds, the progressive ionization caused by the gradual addition of $\mathrm{NaOH}$ generates electrostatic repulsions between the charged carboxylate groups $\left(-\mathrm{COO}^{-}\right)$and led to the uncoiling of the polymer chains in solution. This conformational change exposes the carboxyl groups not yet loaded, requiring a larger volume of $\mathrm{NaOH}$ to be neutralized [8].

Additionally, an abrupt change was not detected in $\mathrm{pH}$ with the addition of small amounts of base, characteristic behavior of polyelectrolyte, showing the largest change of slope in the region near the detectable monomer point of equivalence. Similar behaviors have been reported by several authors $[6,7,37]$.

In Figure 4(b) the titration curves of the graft copolymer (St- $g$-IA) and the native starch (St) are presented. The graph shows that the copolymer has a similar behavior to the homopolymer, varying primarily in the initial $\mathrm{pH}$ which is between the value of the homopolymer and native starch.

When it is compared with the curve of native starch, a higher slope is observed, corresponding to the sudden change in $\mathrm{pH}$ between 4.0 and 9.0, which is due to the dissociation of the acid groups incorporated into the starch. This behavior was also observed in the oxidized starches but with less steep slopes, which suggests that the copolymer showed the best performance in terms of incorporation. The displacement of the copolymer curve indicates that the content of carboxyl groups was larger than the native starch. In general, the order of carboxyl content to the gel fraction obtained was as follows: St- $g$-IA $(0.0954 \%)>$ Ox-St $(0.0696 \%)>$ Ht-St $(0.0655 \%)>$ St $(0.0545 \%)$.

3.5. Degree of Substitution and Potentiometric Titration Curves of Esters. In order to promote the esterification reactions of 


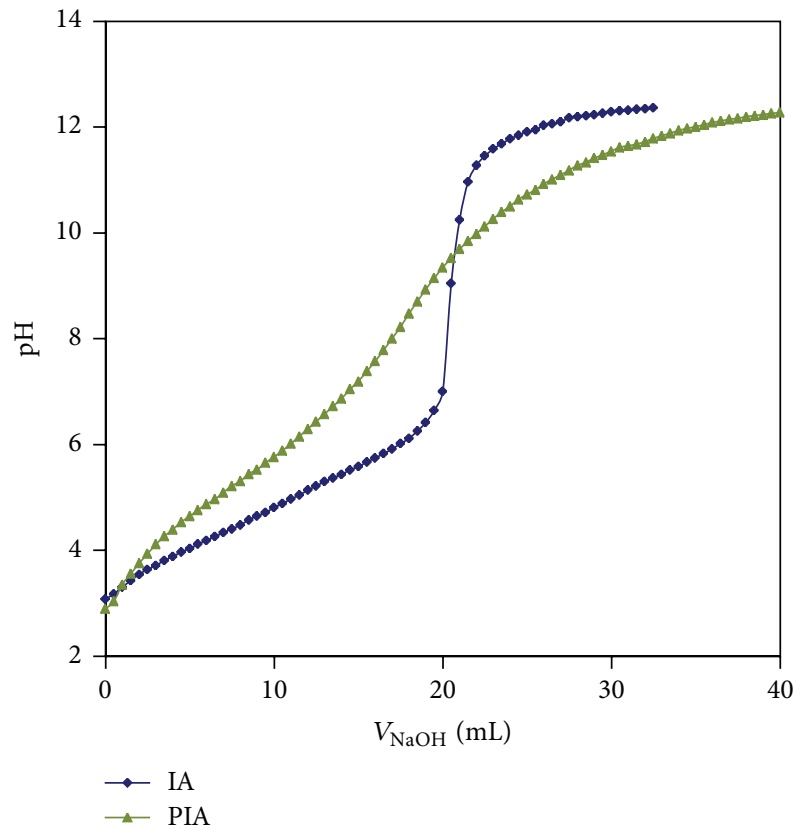

(a)

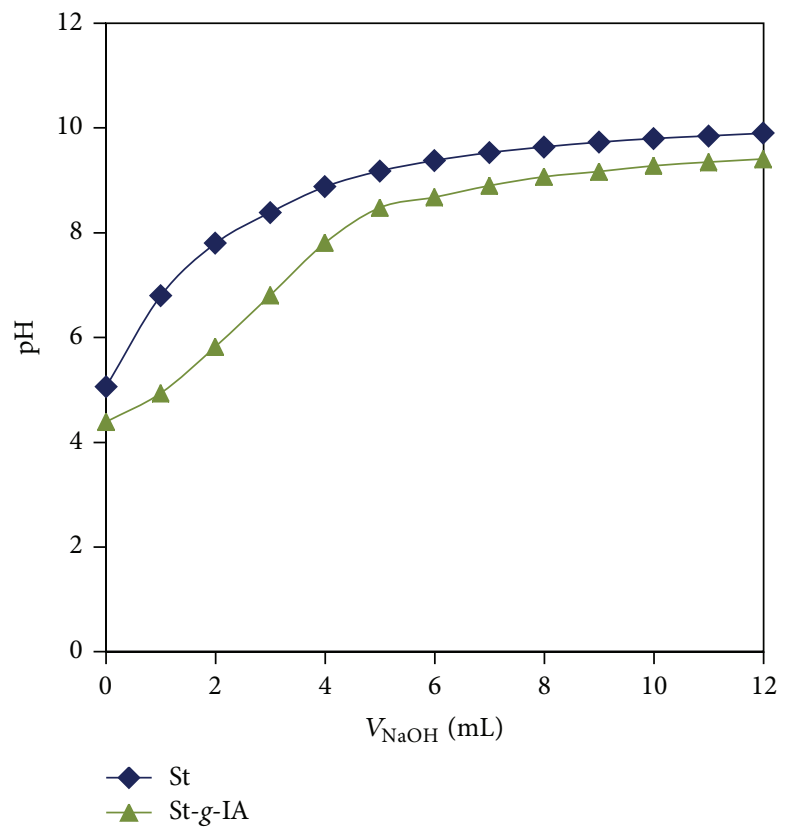

(b)

FIgURE 4: Neutralization curves of itaconic acid (IA) compared to the poly(itaconic acid) (PIA) (a) and of the graft copolymer (St- $g$-IA) compared to the native starch (St) (b).

TABLE 2: Degree of substitution and carboxyl content of starch semiester and diester of itaconic acid.

\begin{tabular}{lcc}
\hline Sample & DS $^{\mathrm{a}}$ & $(\% \mathrm{COOH})^{\mathrm{b}}$ \\
\hline SI & 0.0032 & 0.1395 \\
DI & 0.0030 & 0.0703 \\
\hline${ }^{\mathrm{a}}$ Product without leaching. ${ }^{\mathrm{b}}$ Gel fraction. &
\end{tabular}

starch with IA, high temperatures $\left(80^{\circ} \mathrm{C}\right)$ and addition of $\mathrm{NaOH}$ were used to achieve starch gelatinization. Despite the addition of alkali reactions were catalyzed by acid, due to the large number of substituents added, to shift the equilibrium of the esterification toward the formation of the ester, which caused the lowering of the $\mathrm{pH}$ to values below 2.0. In Figure 5 the schemes of obtaining starch esters are shown, which were produced by the reaction between starch $-\mathrm{OH}$ group IA and $-\mathrm{COOH}$ to generate the starch semi-itaconate (Figure 5(a)). When another load of starch to semiester formed is added the starch di-itaconate (Figure 5(b)) was obtained.

In Table 2, the results of degree of substitution (DS) and carboxyl group content of the products of esterification reactions are presented. The starch semi-itaconate (SI) has a DS similar to the starch diester of (DI). This could indicate that, in the reaction for obtaining the diester, not only the disubstitution with the addition of a second portion of starch but also monosubstitution of the added native starch in the second charge is favored.

Furthermore, the carboxyl group content for the SI gel fraction was higher, since being a semiester has a greater amount of free acid groups. By contrast, in the DI, the carboxyl group content was lower, because it is disubstituted. The disubstitution produces inter- or intramolecular crosslinking, also leaving less free $-\mathrm{COOH}$ groups, and generates products with a lower solubility and the detection of these groups is difficult [38].

Figure 6 shows the titration curves of the starch, the starch semi-itaconate (SI), and the starch di-itaconate (DI) with 0.001 moles $/ \mathrm{L} \mathrm{NaOH}$. It is observed that the curves of the starch and the DI start in a pH near 5.0, while the initial value for the SI is 4.5 .

Additionally, both the curve of SI and the curve of DI are located below and displaced to the right with respect to starch, a result of an increase in the content of acid groups on these derivatives with respect to the starting material. It is also appreciated that there is a notable difference between the curve of the DI and SI; the disubstitution prevents the acid groups which are available to react with the base; in contrast with the semiester, ionization occurs more sharply because one of the carboxyl groups of the substituent is free and available to react with the base. For that reason, in the curve of St no sudden changes in $\mathrm{pH}$ are observed; for the DI this parameter changes from 5 to 9.15 with the addition of $5 \mathrm{~mL}$ of $\mathrm{NaOH}$, while for SI $7 \mathrm{~mL}$ of titrant was required to raise its $\mathrm{pH}$ of 4.5 to 8.57 . In summary, the DI had lower ionization than SI but greater than St, which presented the lowest ionization since it is present in most groups $-\mathrm{OH}$.

3.6. Comparison of the Titration Curves of the Different Types of Products Analyzed. In Figure 7, the titration curves of the products obtained through the three-way change used 


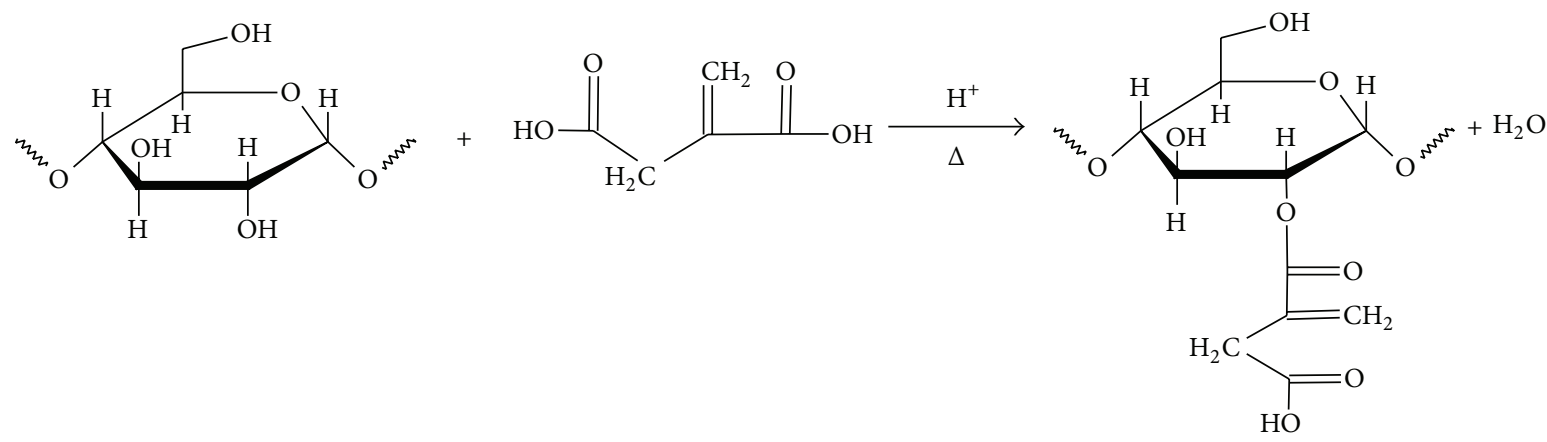

(a)

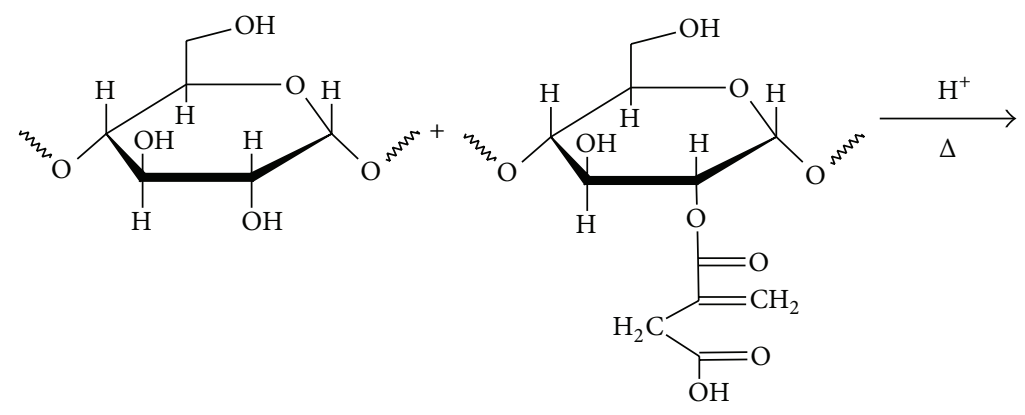

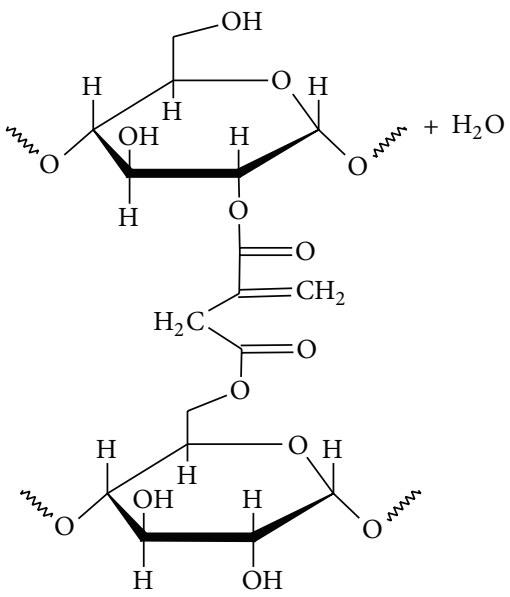

(b)

FIGURE 5: Esterification of starch with itaconic acid to obtain (a) a semiester and (b) the diester.

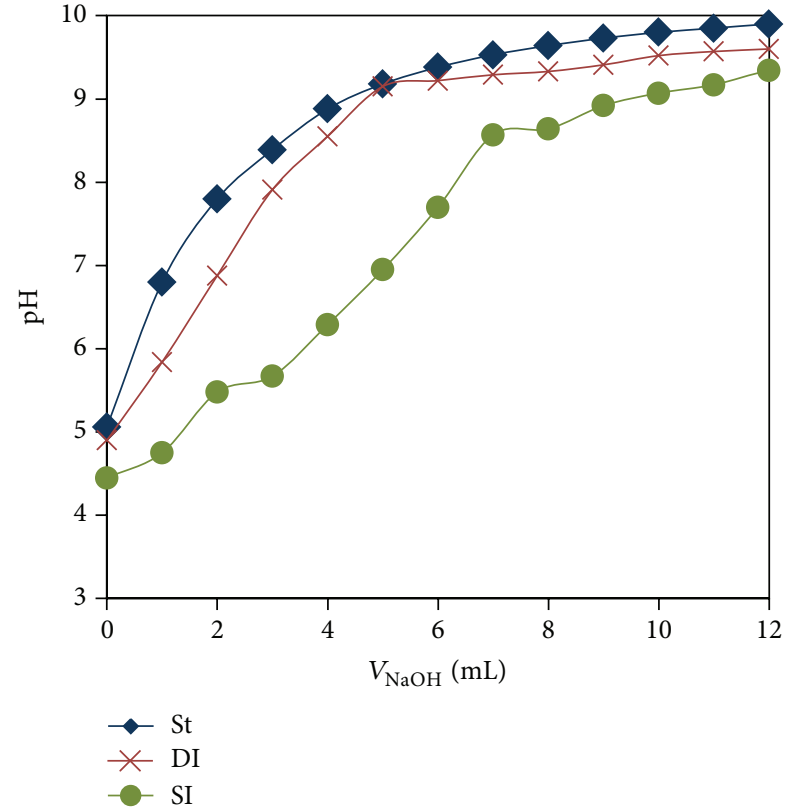

FIGURE 6: Potentiometric titration curves of starch itaconate semiester (SI) and the starch diester itaconate (DI) compared to the native starch $(\mathrm{St})$.

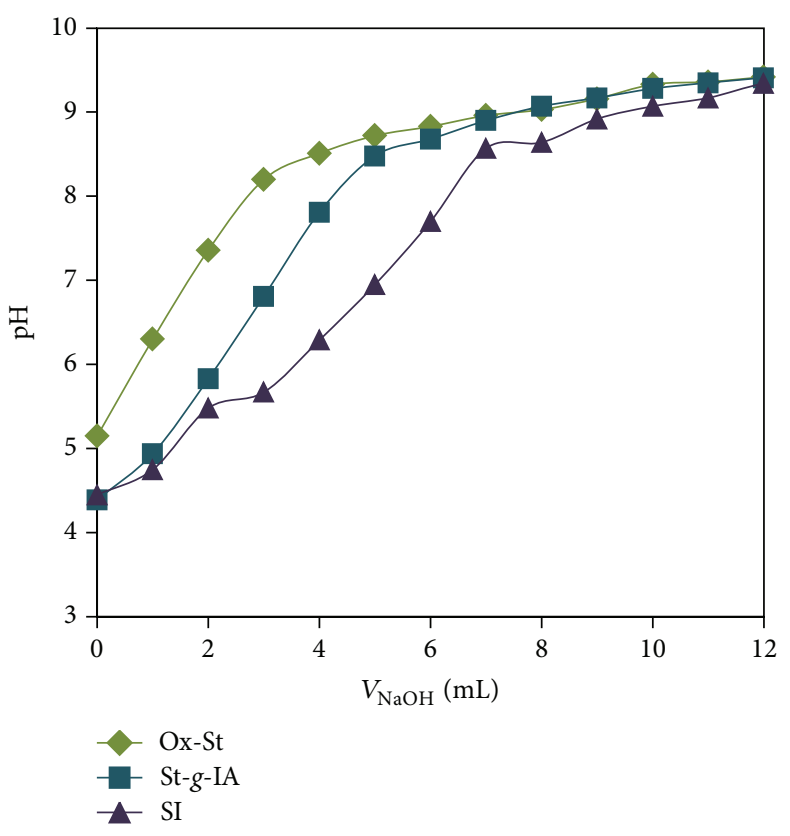

FIgURE 7: Comparison of potentiometric titration curves of the products obtained by the type of modification. 
are shown. By comparing the behavior of polyelectrolyte oxidized starch (Ox-St), the graft copolymer (St-g-IA), and the starch semiester (SI), it is found that the values of initial $\mathrm{pH}$ for the copolymer and the semiester are similar and lower than the Ox-St.

However, it was observed that the largest displacement of the curve is given to SI, so it follows that this derivative has an increased amount of neutralizable acid groups, followed by St- $g$-IA and lastly Ox-St. Therefore, the best way to obtain modified starches with ionizable groups was esterification with itaconic acid and one charge of starch. The shapes of the curves and sudden changes in $\mathrm{pH}$ were explained in the previous subsections.

\section{Conclusion}

Characterization of the native starch and modified starches was achieved by potentiometric titration. By using this technique, each product could be differentiated based on the content of acid groups, thus allowing the selection of the optimal synthetic route to produce modified starches with ionizable groups. The ionization behavior of the itaconic acid and homopolymer was very different, the latter having a $\mathrm{pH}$ change much more attenuated as it is a compound of high molar mass. The graft copolymer had a higher acidity than native starch, including oxidized starches. The ester had a greater number of acid groups than the graft copolymer; therefore, the best way to obtain modified starches with ionizable groups was esterification with itaconic acid, one charge of starch.

\section{Outlook}

Importantly, the use of an automatic titrator and optimizing titration methods could allow obtaining better results. Currently the research group is making efforts to improve the method of determining the degree of substitution of esters and application of potentiometric titration to other polysaccharides and their derivatives.

\section{Conflict of Interests}

The authors declare that there is no conflict of interests regarding the publication of this paper.

\section{Acknowledgments}

The authors thank The Council for Scientific and Technological Development (CONDES) and The Graduate Study Division, Faculty of Engineering, Universidad del Zulia, for financial support.

\section{References}

[1] S. Farris, L. Mora, G. Capretti, and L. Piergiovanni, "Charge density quantification of polyelectrolyte polysaccharides by conductometric titration: an analytical chemistry experiment," Journal of Chemical Education, vol. 89, no. 1, pp. 121-124, 2012.
[2] M. C. C. Azevedo and A. M. V. Cavaleiro, "The acid-base titration of a very weak acid: boric acid," Journal of Chemical Education, vol. 89, no. 6, pp. 767-770, 2012.

[3] J. Hurek and J. Nackiewicz, "A simple method for the consecutive determination of protonation constants through evaluation of formation curves," Journal of Chemical Education, vol. 90, no. 5, pp. 604-608, 2013.

[4] A. Katchalsky and P. Spitnik, "Potentiometric titrations of polymethacrylic acid laboratory of macromolecular chemistry, Hebrew University, Jerusalem," Journal of Polymer Science, vol. 2, no. 4, pp. 432-446, 1947.

[5] U. Lappan, U. Geißler, M. Oelmann, and S. Schwarz, "Apparent dissociation constants of polycarboxylic acids in presence of polycations," Colloid and Polymer Science, vol. 290, no. 16, pp. 1665-1670, 2012.

[6] S. PoŁowiński, "Study of poly(itaconic acid) in aqueous solutions," Polymers, vol. 51, no. 4, pp. 270-275, 2006.

[7] D. Stawski and S. Polowinski, "Polymerization of itaconic acid," Polimery, vol. 50, no. 2, pp. 118-165, 2005.

[8] S. Banerjee, K. Sen, T. K. Pal, and S. K. Guha, "Poly(styrene-comaleic acid)-based $\mathrm{pH}$-sensitive liposomes mediate cytosolic delivery of drugs for enhanced cancer chemotherapy," International Journal of Pharmaceutics, vol. 436, no. 1-2, pp. 786-797, 2012.

[9] O. Colombani, E. Lejeune, C. Charbonneau, C. Chassenieux, and T. Nicolai, "Ionization of amphiphilic acidic block copolymers," The Journal of Physical Chemistry B, vol. 116, no. 25, pp. 7560-7565, 2012.

[10] F. Vilaplana, J. Hasjim, and R. G. Gilbert, "Amylose content in starches: toward optimal definition and validating experimental methods," Carbohydrate Polymers, vol. 88, no. 1, pp. 103-111, 2012.

[11] L. Li, H. Jiang, M. Campbell, M. Blanco, and J.-L. Jane, "Characterization of maize amylose-extender (ae) mutant starches. Part I. Relationship between resistant starch contents and molecular structures," Carbohydrate Polymers, vol. 74, no. 3, pp. 396-404, 2008.

[12] Y. Song and J. Jane, "Characterization of barley starches of waxy, normal, and high amylose varieties," Carbohydrate Polymers, vol. 41, no. 4, pp. 365-377, 2000.

[13] D. X. Duan, E. Donner, Q. Liu, D. C. Smith, and F. Ravenelle, "Potentiometric titration for determination of amylose content of starch-a comparison with colorimetric method," Food Chemistry, vol. 130, no. 4, pp. 1142-1145, 2012.

[14] H. Yangcheng, H. Jiang, M. Blanco, and J. L. Jane, "Characterization of normal and waxy corn starch for bioethanol production," Journal of Agricultural and Food Chemistry, vol. 61, no. 2, pp. 379-386, 2013.

[15] X. Jiang, L. Chen, and W. Zhong, "A new linear potentiometric titration method for the determination of deacetylation degree of chitosan," Carbohydrate Polymers, vol. 54, no. 4, pp. 457-463, 2003.

[16] Y. Zhang, X. Zhang, R. Ding, J. Zhang, and J. Liu, "Determination of the degree of deacetylation of chitosan by potentiometric titration preceded by enzymatic pretreatment," Carbohydrate Polymers, vol. 83, no. 2, pp. 813-817, 2011.

[17] L. F. Zemljič, D. Čakara, N. Michaelis, T. Heinze, and K. S. Kleinschek, "Protonation behavior of 6-deoxy-6-(2-aminoethyl)amino cellulose: a potentiometric titration study," Cellulose, vol. 18, no. 1, pp. 33-43, 2011. 
[18] L. J. C. B. Carvalho, C. R. Batista De Souza, J. C. de Mattos Cascardo, C. Bloch Jr., and L. Campos, "Identification and characterization of a novel cassava (Manihot esculenta Crantz) clone with high free sugar content and novel starch," Plant Molecular Biology, vol. 56, no. 4, pp. 643-659, 2004.

[19] T. V. Shevchenko, E. A. Kondratov, E. V. Ul'rich, A. M. Popov, V. S. Lobanova, and I. O. Tokmakova, "On the variation of physicochemical properties of starch samples treated by microwave radiation," Russian Journal of Applied Chemistry, vol. 86, no. 1, pp. 127-131, 2013.

[20] N. E. Ihegwuagu, M. O. Omojola, M. O. Emeje, and O. O. Kunle, "Isolation and evaluation of some physicochemical properties of Parkia biglobosa starch," Pure and Applied Chemistry, vol. 81, no. 1, pp. 97-104, 2009.

[21] D. A. Alabi, O. R. Akinsulire, and M. A. Sanyaolu, "Qualitative determination of chemical and nutritional composition of Parkia biglobosa (Jacq.) Benth," African Journal of Biotechnology, vol. 4, no. 8, pp. 812-815, 2005.

[22] R. F. Tester, J. Karkalas, and X. Qi, "Starch-composition, fine structure and architecture," Journal of Cereal Science, vol. 39, no. 2, pp. 151-165, 2004.

[23] N. Kavlani, V. Sharma, and L. Singh, "Various techniques for the modification of starch and the applications of its derivatives," International Research Journal of Pharmacy, vol. 3, no. 5, pp. 2531, 2012.

[24] Y. Zheng, S. Hua, and A. Wang, "Adsorption behavior of $\mathrm{Cu}^{2+}$ from aqueous solutions onto starch-g-poly(acrylic acid)/ sodium humate hydrogels," Desalination, vol. 263, pp. 170-175, 2010.

[25] E. Orozco-Guareño, F. Santiago-Gutiérrez, J. L. Morán-Quiroz et al., "Removal of $\mathrm{Cu}(\mathrm{II})$ ions from aqueous streams using poly(acrylic acid-co-acrylamide) hydrogels," Journal of Colloid and Interface Science, vol. 349, no. 2, pp. 583-593, 2010.

[26] C. S. Marvel and T. H. Shepherd, "Polymerization reactions of itaconic acid and some of its derivatives," Journal of Organic Chemistry, vol. 24, no. 5, pp. 599-605, 1959.

[27] S. H. Tay, S. C. Pang, and S. F. Chin, "Facile synthesis of starchmaleate monoesters from native sago starch," Carbohydrate Polymers, vol. 88, no. 4, pp. 1195-1200, 2012.

[28] S. C. Pang, S. F. Chin, S. H. Tay, and F. M. Tchong, "Starchmaleate-polyvinyl alcohol hydrogels with controllable swelling behaviors," Carbohydrate Polymers, vol. 84, no. 1, pp. 424-429, 2011.

[29] S. Chattopadhyay, R. S. Singhal, and P. R. Kulkarni, "Optimisation of conditions of synthesis of oxidised starch from corn and amaranth for use in film-forming applications," Carbohydrate Polymers, vol. 34, no. 4, pp. 203-212, 1997.

[30] R. J. Smith, "Production and use of hypochlorite oxidized starches," in Starch Chemistry and Technology, R. L. Whistler and E. F. Paschall, Eds., vol. 2, pp. 620-625, Academic Press, New York, NY, USA, 1967.

[31] J. F. Zhu, G. H. Zhang, and Z. C. Lai, "Synthesis and characterization of maize starch acetates and its biodegradable film," Polymer-Plastics Technology and Engineering, vol. 46, no. 12, pp. 1135-1141, 2007.

[32] D. Chen, C. Yand, and X. Qiu, "Aqueous polymerization of maleic acid and cross-linking of cotton cellulose by poly(maleic acid)," Industrial \& Engineering Chemistry Research, vol. 44, no. 21, pp. 7921-7927, 2005.

[33] P. Lanthong, R. Nuisin, and S. Kiatkamjornwong, "Graft copolymerization, characterization, and degradation of cassava starch-g-acrylamide/itaconic acid superabsorbents," Carbohydrate Polymers, vol. 66, no. 2, pp. 229-245, 2006.

[34] X. Yi, S. Zhang, and B. Ju, "Preparation of water-soluble oxidized starch with high carbonyl content by sodium hypochlorite," Starch: Stärke, vol. 66, no. 1-2, pp. 115-123, 2014.

[35] F. F. Takizawa, G. de Oliveira, F. E. Konkel, and I. M. Demiate, "Characterization of tropical starches modified with potassium permanganate and lactic acid," Brazilian Archives of Biology and Technology, vol. 47, no. 6, pp. 921-931, 2004.

[36] S. Dash, S. Patel, and B. K. Mishra, "Oxidation by permanganate: synthetic and mechanistic aspects," Tetrahedron, vol. 65 , no. 4 , pp. 707-739, 2009.

[37] Z. Mao and C. Yang, "Polymeric multifunctional carboxylic acids as crosslinking agents for cotton cellulose: poly(itaconic acid) and in situ polymerization of itaconic acid," Journal of Applied Polymer Science, vol. 79, pp. 319-326, 2000.

[38] J. Singh, L. Kaur, and O. J. McCarthy, "Factors influencing the physico-chemical, morphological, thermal and rheological properties of some chemically modified starches for food applications-a review," Food Hydrocolloids, vol. 21, no. 1, pp. 122, 2007. 

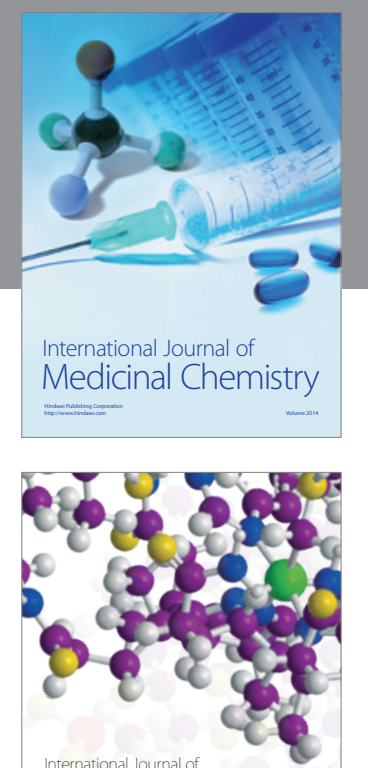

\section{Carbohydrate} Chemistry

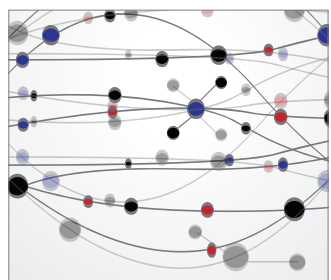

The Scientific World Journal
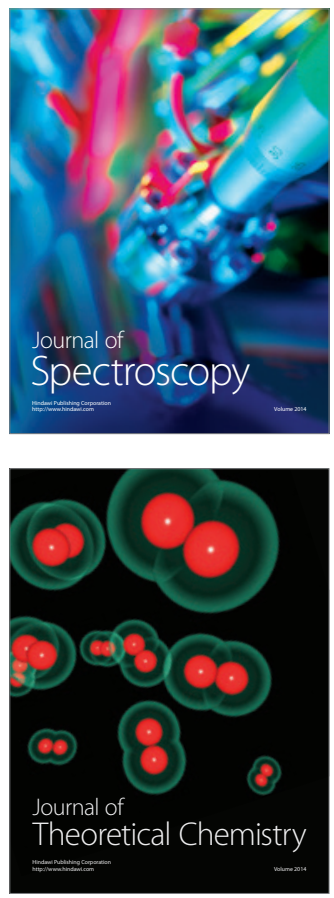
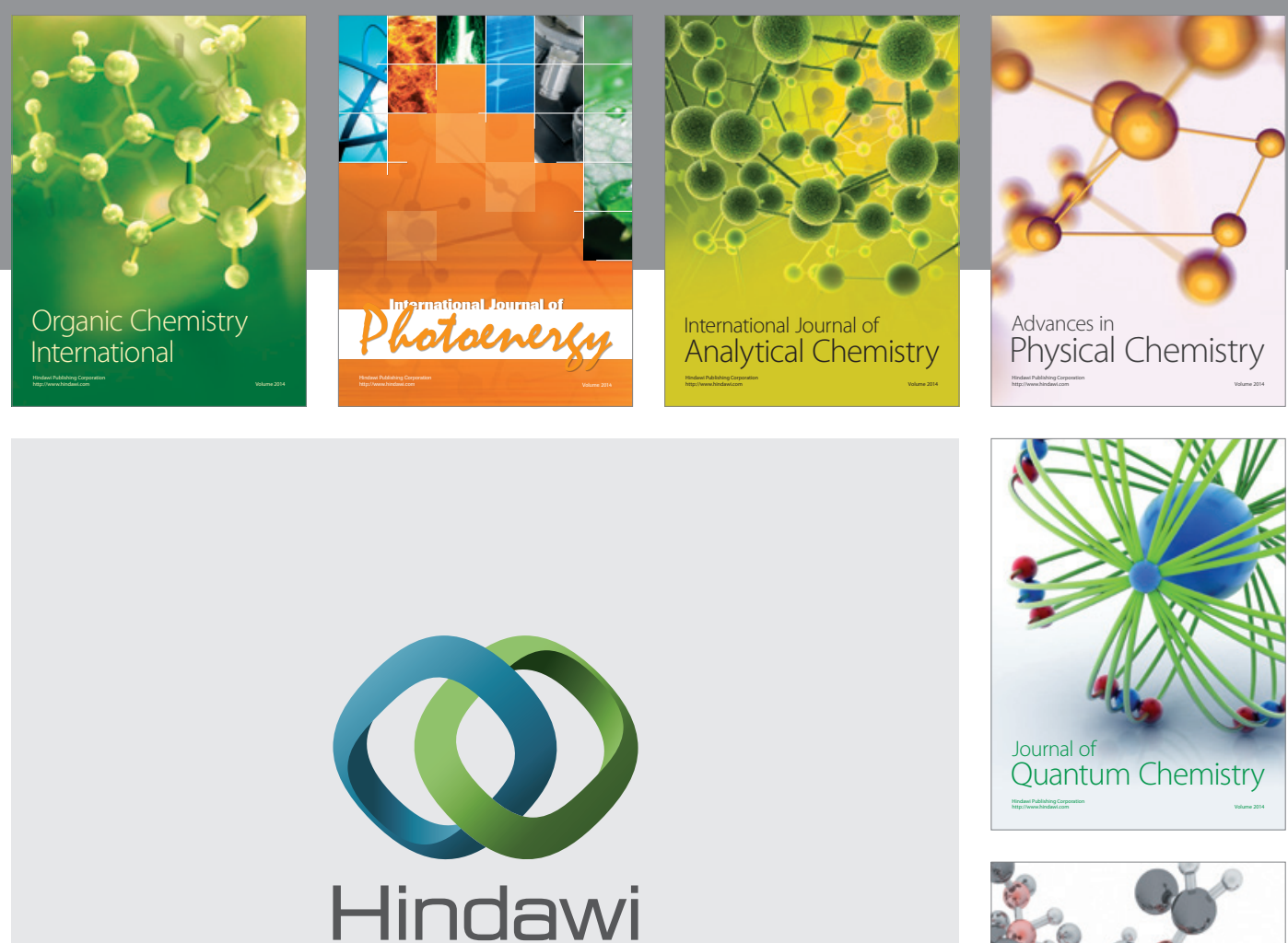

Submit your manuscripts at

http://www.hindawi.com

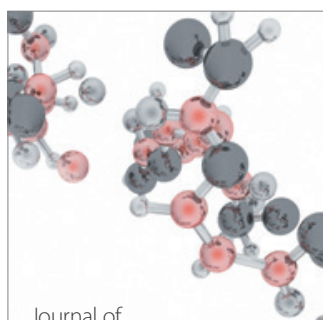

Analytical Methods

in Chemistry

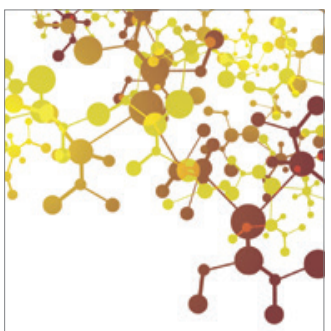

Journal of

Applied Chemistry

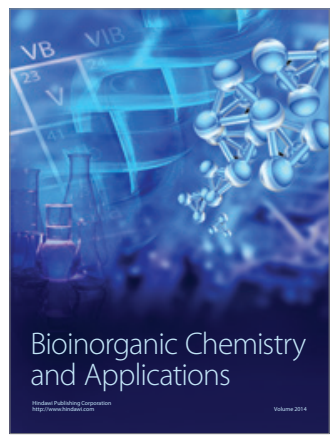

Inorganic Chemistry
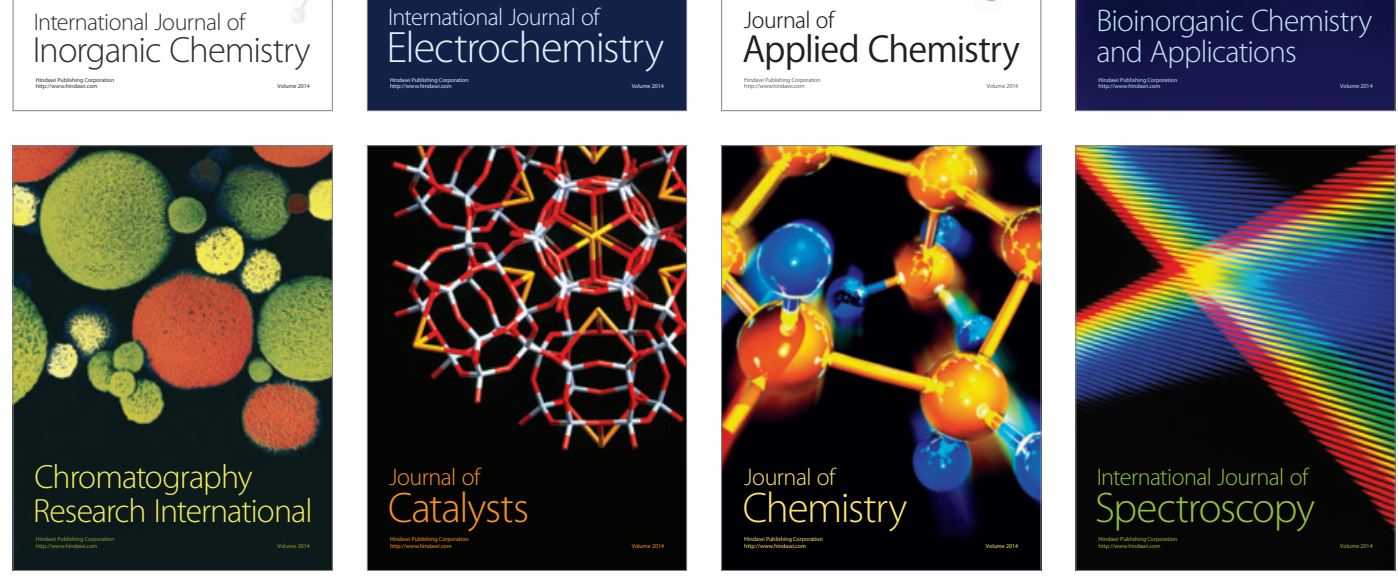